\begin{abstract}
Iranica
Abstracta Iranica Revue bibliographique pour le domaine irano-aryen

Volume 34-35-36 | 2017

Comptes rendus des publications de 2011-2013
\end{abstract}

\title{
Peter Magee. Iron Age southeastern Iran
}

\section{Rémy Boucharlat}

\section{(2) OpenEdition}

\section{Journals}

Édition électronique

URL : http://journals.openedition.org/abstractairanica/42124

DOI : 10.4000/abstractairanica.42124

ISSN : 1961-960X

Éditeur :

CNRS (UMR 7528 Mondes iraniens et indiens), Éditions de l'IFRI

Référence électronique

Rémy Boucharlat, "Peter Magee. Iron Age southeastern Iran », Abstracta Iranica [En ligne], Volume 34-35-36 | 2017, document 117, mis en ligne le 30 juillet 2017, consulté le 05 octobre 2020. URL http://journals.openedition.org/abstractairanica/42124; DOI : https://doi.org/10.4000/ abstractairanica. 42124

Ce document a été généré automatiquement le 5 octobre 2020.

Tous droits réservés 


\title{
Peter Magee. Iron Age southeastern
}

\section{Iran}

\author{
Rémy Boucharlat
}

\section{RÉFÉRENCE}

Peter Magee. «Iron Age southeastern Iran », in: D.T. Potts, ed., The Oxford Handbook of Ancient Iran. New York, Oxford University Press, 2013, p. 493-499.

1 Cet article est l'un des plus courts du volume, car la documentation est pauvre pour cette région qui représente pourtant un quart du territoire de l'Iran, faute de recherches, en particulier pour le $\mathrm{I}^{\mathrm{er}}$ mill. av. J.-C. et le millénaire suivant. L'A. observe une réémergence du peuplement dans les premiers siècles du $I^{\text {er }}$ mill. après un net déclin net $\mathrm{au} \mathrm{II}^{\mathrm{e}}$ mill., sans doute due en partie à une baisse notable des précipitations. Mais les documents sont rares, même si l'A. suggère une expansion du peuplement à partir du $\mathrm{VII}^{\mathrm{e}}$ siècle. Il se fonde principalement sur le seul site de Tepe Yahya et l'hypothèse, qui reste à démontrer, de l'introduction de l'irrigation par la technique du qanāt.

\section{AUTEURS}

\section{RÉMY BOUCHARLAT}

UMR 5133 CNRS-Université de Lyon 